\title{
COVID-19 infection associated with autoimmune hemolytic anemia
}

\author{
Antoine Capes $^{1} \cdot$ Sarah Bailly $^{2} \cdot$ Philippe Hantson $^{1}$ (1) $\cdot$ Ludovic Gerard ${ }^{1} \cdot$ Pierre-François Laterre ${ }^{1}$
}

Received: 22 May 2020 / Accepted: 9 June 2020 / Published online: 16 June 2020

(C) Springer-Verlag GmbH Germany, part of Springer Nature 2020

\section{Dear Editor,}

A 62-year-old man with a medical past history of arterial hypertension and heavy smoking was ongoing radiochemotherapy for an oropharyngeal squamous cell carcinoma (cT3N0M0). Three days after the first cisplatin injection, the patient started a dry cough without fever. A nasopharyngeal swab was positive for Covid-19 (tested by PCR). A week later, he presented a marked asthenia and was referred to the emergency room. Physical examination showed fever and mild dyspnea, with a low oxygen saturation on room air. The patient was perfectly conscious, and there was no evidence of motor deficit. Chest X-ray showed bilateral lung infiltrates. The laboratory examination results were as follows: white blood cell count (WBC) 6620/ $\mu \mathrm{L}$, lymphocyte count $500 / \mu \mathrm{L}(\mathrm{Nl}, 800$ 5000 ), normal neutrophil count, platelet count $101,000 / \mu \mathrm{L}(\mathrm{Nl}$, 150,000-450,000), hemoglobin $12 \mathrm{~g} / \mathrm{dL}(\mathrm{Nl}, 13.3-16.7)$, CRP $45 \mathrm{mg} / \mathrm{L}(\mathrm{Nl},<5)$, normal serum creatinine, LDH $307 \mathrm{IU} / \mathrm{L}(\mathrm{Nl}$, $<250)$, and bilirubin $0.7 \mathrm{mg} / \mathrm{dL}(\mathrm{Nl},<1.2)$.

Fourteen days after the first respiratory symptoms, he was transferred to the intensive care unit (ICU), and orotracheal intubation was required soon after admission. Anemia also deteriorated progressively with a rise of LDH level. On day 16, the patient developed acrocyanosis. Laboratory tests showed lymphocyte count $120 / \mu \mathrm{L}$, normal neutrophil count, platelet count $145,000 / \mu \mathrm{L}$, hemoglobin $6.9 \mathrm{~g} / \mathrm{dl}$, LDH $726 \mathrm{IU} / \mathrm{L}$, reticulocyte count $40,000 / \mu \mathrm{L}(\mathrm{Nl}, 30,000-100,000)$ raising to $231,000 / \mu \mathrm{L}$ 10 days later, potassium $6.78 \mathrm{mmol} / \mathrm{L}(\mathrm{Nl}, 3.5-5)$, haptoglobin $0.13 \mathrm{~g} / \mathrm{L}$ (Nl, 0.3-2), CRP $335 \mathrm{mg} / \mathrm{L}$, normal creatinine, and bilirubin $1.3 \mathrm{mg} / \mathrm{dL}$. Blood smear showed numerous red blood cell agglutination, schizocytes $<1 \%$. Direct Coombs test was

Philippe Hantson

philippe.hantson@uclouvain.be

1 Department of Intensive Care, Cliniques St-Luc, Université catholique de Louvain, Avenue Hippocrate, 10,

1200 Brussels, Belgium

2 Department of Haematology, Cliniques St-Luc, Université catholique de Louvain, Brussels, Belgium positive for $\mathrm{C} 3 \mathrm{~b}$ and negative for IgG. Cold agglutinins were positive (titer 1/16384) and anti-I (titer 1/1024). Antinuclear antibodies were positive (titer 1/160), ENA screening negative, and antiphospholipid negative. A multiplex PCR testing performed on tracheal aspiration was negative for Mycoplasma pneumoniae, Legionella pneumophila, Chlamydia pneumoniae, Adenovirus, and Influenza. Serology testing was negative for $\mathrm{HBV}, \mathrm{HCV}$, and $\mathrm{HIV}$, while IgG antibodies were found for EBV and CMV and IgM and IgG antibodies for Mycoplasma pneumoniae. Leucocytes immunophenotyping performed on peripheral blood showed lymphopenia without evidence of clonality. There was an oligoclonal pattern of gammaglobulins at serum protein electrophoresis; light chains kappa/lambda ratio was normal. The patient received 8 units of red packet cells over 1 week. At 6-week follow-up, the patient is slowly recovering from respiratory failure.

While the main target of Covid-19 remains the lung, with respiratory failure and acute respiratory distress syndrome for the most severe cases, extra-pulmonary complications are now increasingly reported. Among autoimmune manifestations, autoimmune hemolytic anemia (AIHA) is an unusual finding. Autoimmune hemolytic anemia (with warm or cold antibodies) was recently described in 7 patients with Covid-19 disease $[1,2]$. The delay between Covid-19 and hemolytic manifestations ranged from 4 to 13 days. Four patients had indolent $\mathrm{B}$ lymphoid malignancy either already known or discovered at the time of hemolytic episode. The chronological sequence in our case suggests that Covid-19 was the causal factor for AIHA. Temporal events and exclusion of other potential causes support this hypothesis. Indeed, our patient had a history of oropharyngeal carcinoma which is not usually considered as a triggering factor for autoimmune hemolytic anemia. The interpretation of Mycoplasma pneumonia serology should also be extremely careful, as IgM antibodies do not mandatory indicate a recent infection [3]. In our case, PCR testing was negative on the sputum, and there was no significant increase in IgG antibody titer over time. Among other hematological complications of Covid-19 infection, autoimmune thrombocytopenia and antiphospholipid syndrome were also described, but not present in our observation $[1,4,5]$. 


\section{Compliance with ethical standards}

Conflict of interest The authors declare that they have no conflict of interest.

Ethical approval All procedures performed in studies involving human participants were in accordance with the ethical standards of the institutional and/or national research committee and with the 1964 Helsinki declaration and its later amendments or comparable ethical standards.

Informed consent An informed consent was obtained from the relatives.

\section{References}

1. Lazarian G, Quinquenel A, Bellal M, et al. (2020) Autoimmune hemolytic anemia associated with Covid-19 infection. Br J
Haematol. https://doi.org/10.1111/bjh.16794. [published online ahead of print, 2020 May 6]

2. Lopez C, Kim J, Pandey A, Huang T, DeLoughery TG (2020) Simultaneous onset of COVID-19 and autoimmune hemolytic anemia. Br J Haematol. https://doi.org/10.1111/bjh.16786

3. Meyer Sauteur PM, Jacobs BC, Spuesens EB et al (2014) Antibody responses to mycoplasma pneumoniae: role in pathogenesis and diagnosis of encephalitis? PLoS Pathog 10(6):e1003983

4. Zhang Y, Xiao M, Zhang S, Xia P, Cao W, Jiang W, Chen H, Ding X, Zhao H, Zhang H, Wang C, Zhao J, Sun X, Tian R, Wu W, Wu D, Ma J, Chen Y, Zhang D, Xie J, Yan X, Zhou X, Liu Z, Wang J, du B, Qin Y, Gao P, Qin X, Xu Y, Zhang W, Li T, Zhang F, Zhao Y, Li Y, Zhang S (2020) Coagulopathy and antiphospholipid antibodies in patients with Covid-19. N Engl J Med 382(17):e38

5. Zulfiqar AA, Lorenzo-Villalba N, Hassler P, Andrès E (2020) Immune thrombocytopenic purpura in a patient with Covid-19. N Engl J Med 382(18):e43

Publisher's note Springer Nature remains neutral with regard to jurisdictional claims in published maps and institutional affiliations. 